\title{
V. F. SAMPEDRO BLANCO (ed.). 13-M. Multitudes on-line. Madrid, Los Libros de la Catarata, 2005.
}

Tal vez sea el aburrimiento que genera el juego político institucionalizado tendente al electoralismo más banal, o la tediosa e indiferente alternancia bipartidista, o la misma desustancialización y pasividad política de la ciudadanía ${ }^{1}$ convertida en una masa de votantes, lo que ha llevado a sobredimensionar la relevancia de ciertos acontecimientos de movilización social. También, por qué no decirlo, ha contado la excitación, acompañada a veces de un cierto tono narcisista $^{2}$, que supone haber participado directa o indirectamente en ellos. Eso explica la publicación, de un tiempo a esta parte, de un puñado de libros de diferente calado y propósito sobre los acontecimientos que siguieron al atentado del 11 de marzo de 2004 y que curiosamente se consideran culminados con el supues-

1 El estatuto jurídico de «ciudadano», ha pasado de ser entendido como natural de un Estado, a adquirir un contenido positivo. En cuanto atributo, «ciudadano» describe en general todo lo que es aplicado y consciente de sus responsabilidades, e indica una cierta dosis de lealtad política, en tanto que la antigua lucha de clases se ha visto sustituida por la participación política de los ciudadanos.

${ }^{2}$ Se hace difícil interpretar el epígrafe «Nos autoinculpamos» de libro comentado, donde uno a uno los autores aportan su DNI e invitan a rellenar un formulario de autoinculpación de los supuestos delitos electorales cometidos el 13-M (quejándose en otro lugar de las pocas personas que lo han hecho, $p$. 300 ), así como la contraportada y la banda que acompaña el libro y que insisten en lo mismo («fuimos todos»). Se hace difícil porque se halla entre lo audaz, lo patético y lo narcisista. En esto último tiene que ver el propio estilo de escritura, con mucho de vivencia experimentada y rebosante de autocitas, no sólo por parte del editor sino también de algunos otros autores. to vuelco electoral ${ }^{3}$. En esta línea se inscribe el presente volumen que comentamos editado por Víctor F. Sampedro en la editorial Los Libros de la Catarata. Von un encomiable esfuerzo de trabajo empírico, su propósito inicial se dedica, como se indica en el capítulo que lo abre, a intentar desmontar la tesis conspirativa $y$, a diferencia de otros que reviven metáforas revolucionarias o padecen de una fuerte tecnofilia, rastrea las movilizaciones previas que van desde la crisis del Prestige o la oposición a la guerra de Irak para explicar las jornadas posteriores a dicho atentado y que desembocan en las elecciones que llevaron la victoria de la oposición institucional. Pero en realidad la tesis que se desliza en los múltiples artículos que firma su editor es que el 13 de marzo fue un acto de desobediencia civil donde «una parte sustancial de la ciudadanía recobró su voz y al día siguiente la trasladó a las urnas» (p. 17).

En líneas generales, y como todo producto de una compilación, en este caso de nueve capítulos realizada por diversos au-

${ }^{3}$ No es este el espacio para desarrollar con amplitud el carácter de las últimas elecciones generales. Bastaría trabajar con dos hechos para dotarle de un carácter más previsible y cuestionar el atributo de vuelco electoral con que se ha descrito dicho acontecimiento: por una parte, el principal partido de la oposición institucional obtuvo un millón de votos más que en el partido del gobierno en las elecciones municipales celebradas un año antes; por otra parte no hay que olvidar el peculiar sistema electoral de definición proporcional pero de inspiración mayoritaria generado por el elevado número de circunscripciones y el desequilibrado peso de cada de ellas en su representación parlamentaria, lo que lleva aparejado que un pequeño cambio en el número de votos pueda suponer la alteración de la mayoría o minoría parlamentarias. 
tores, el libro en cuestión tiende a la irregularidad. Máxime si tenemos en cuenta la desarticulada estructura general achacable a la poca presteza de la coordinación y la sensación de apresuramiento en cuanto al montaje. Así nos encontramos con que los artículos tienen contenidos solapados o pierden el hilo argumental, o bien no son congruentes entre sí, ni mantienen el mismo enfoque ni persiguen las mismas tesis; y por ello veremos desfilar artículos basados en análisis cualitativos con curiosas innovaciones metodológicas, otros de análisis cuantitativo de contenido de noticias, con otros cuantitativos con datos secundarios y por último otros de carácter más teórico. No obstante esta dispersión, que en principio debería ser enriquecedora, no lograr cubrir todos los ángulos posibles: existe una tendencia a concentrarse en los aspectos mediáticos y comunicativos, tal vez por la procedencia académica e investigadora de los autores; o a centrase movilización en la calle, pero hay poca dedicación a otros aspectos territoriales que superen el ámbito madrileño, $o$ a aspectos de carácter económico, a otros ámbitos de lo político, o vinculados a la situación internacional, etc. En cualquier caso, los diferentes artículos aparecen más o menos unidos por el análisis empírico de las movilizaciones del 13-M en Madrid, aunque su caracterización teórica final adolece de un cierto sesgo ensayista en tanto que el concepto que da título al volumen, esto es «multitudes on-line», no se sigue en absoluto de los capítulos, por lo que parece más bien responsabilidad exclusiva del editor Víctor F. Sampedro que es quien lo firma. El libro se acompaña, entre otras cosas, de un CD con un documental « 4 días de marzo» que trata de ilustrar en parte lo que puede leerse en el libro aunque se queda en lo anecdótico de las crónicas periodísticas, y de imágenes inéditas de las manifestaciones convocadas en esa fecha.
Desde el punto de vista metodológico cabe cuestionar los diferentes capítulos que utilizan técnicas cualitativas de producción de datos a través de grupos de discusión. Ya sabemos que se trata de una técnica que busca no la representatividad sino más bien la significación de los datos producidos, pero ello no es óbice para alcanzar una cierta dispersión de la muestra, así como un número mínimo de grupos realizados. Dichos criterios no se cumplen en ninguno de los casos y en ocasiones asistimos a deslices metodológicos y epistemológicos graves. Así, en el capítulo dos se nos indica que se han formado «cuatro grupos homogéneos» compuestos por estudiantes de las licenciaturas de Comunicación de la Universidad Rey Juan Carlos. La comodidad de utilizar a los propios alumnos va en este caso reñida con el necesario carácter artificial de todo grupo de discusión, por no hablar del dislate producido en el diseño muestral, y permite anotarse un tanto a aquellos que propugnan que las metodologías cualitativas son propias de una actitud perezosa. Cabe además añadir que se plantea como novedad metodológica lo que no constituye sino una aberración -los grupos de discusión tipo panel-, aunque bien mirado, dado que los grupos constituidos son naturales, esta tergiversación acaba por no notarse.

La mala conciencia de este apresuramiento no se disuelve al apelar a «un cierto equilibrio de voces ideológicas y una proporción entre sexos que reproduce con bastante fidelidad su presencia en las titulaciones universitarias de Comunicación», puesto que de esta argumentación lo que se deduce es un despropósito: que la variable principal del trabajo de campo es precisamente ser estudiante de Comunicación. Tampoco se diluye esta ligereza al constar el «significado y relevancia social» de dichos grupos, puesto que «estos jóvenes eran el principal objetivo (en el 
sentido de blanco, target) de la convocatoria del 13-M, el sector social más proclive a tomar parte en la desobediencia civil» (p. 30). ¿Cómo sabemos esto?, ¿por qué son el grupo más proclive a la desobediencia? Para responderlo no queda otra solución que apelar a la ciencia infusa o a la intuición militante, aspectos que volverán a aparecer en sucesivos capítulos cuando se indique por ejemplo que estos grupos «reflejan el peso de los sectores más proclives a la crítica y la movilización social y, por tanto, a organizar o secundar el 13-M en Madrid». Lo curioso estriba en que ni siquiera dicha presunción se cumple de manera significativa por las respuestas dadas por los participantes en tales grupos, aunque da la sensación de que eso es lo de menos: basta con encontrar en aquellos que efectivamente se han movilizado las claves que coinciden con los motivos esgrimidos por los analistas, lo cual acarrea que el discurso sobre el objeto sea una simple proyección de una relación inconsciente con el objeto que obliga a éste a ser más o menos de lo que realmente es. Este subjetivismo se plasma substancialmente en el análisis de las posiciones definidas por los grupos, ante todo las de aquellas más cercanas a la posición de los investigadores, de modo que se alcanza una confusión interesada entre lo que el grupo dice y las tesis de estos últimos y que no es otra sino interpretar el 13-M como una reacción extrema en forma de desobediencia civil iniciado por la izquierda social ante un abuso de poder que parecía intolerable o bien como denuncia del fraude informativo. Podemos hasta estar de acuerdo con dicha tesis, pero no que se deduzca de un trabajo de campo realizado del modo antes descrito, puesto que el análisis de dicho trabajo, que no las citas de los participantes, al resultar redundante con las tesis sostenidas desde el principio arroja dudas de subjetividad sobre dichas tesis que aparecen encerra- das en una autorreferencialidad sin el efecto crítico pretendido.

De ahí que surjan múltiples interrogantes que nunca se ven respondidos: ¿por qué se puede considerar una movilización inusual hasta entonces en una democracia?, ¿por qué el colapso del sistema político e informativo de la última legislatura tiene como pobre resultado un mero cambio de gobierno dentro de un rígido sistema de partidos donde la alternativa bipartidista es la regla?, ¿por quiénes fueron respaldadas las concentraciones de la tarde del 13-M?, ¿existía tan claramente la conciencia de que cumplían «las funciones democráticas de la desobediencia civil»? Más bien parecen constituir alegatos metateóricos de los autores, puesto que a los jóvenes objeto de la investigación no se les concede en sus actos políticos (como el voto) sino «factores más instrumentales y racionales que ideológicos» según la discutible hipótesis de J.J. González y O. Salido ( El voto de los jóvenes», 2003). De esta forma, si en su decisión electoral caracterizada a través del «voto instrumental» influyeron poco factores como la simpatía, la proximidad ideológica o la lealtad y pesó más bien el cálculo estratégico, la actitud vigilante de los responsables políticos, ¿por qué el abuso de poder del partido gobernante no llevó a una movilización masiva el 13-M?, o por el contrario, ¿por qué se identifica su voto simplemente como «de castigo" y no contiene unas orientaciones más «instrumentales y racionales» que ideológicas? Creemos que se trata de la mala unión de unas perspectivas teóricas, por lo demás problemáticas, con los deberes no resueltos del trabajo de investigación.

El capítulo tercero utiliza por su parte sólo tres grupos de discusión escogidos en principio a partir de un rango más amplio (que corresponde no obstante al ámbito docente de los autores) y siguiendo otros criterios: votantes por vez primera 
en elecciones generales, su relación con las nuevas tecnologías (no se indica cómo se mide este factor) y su condición universitaria para la cual se invoca, con cierta humildad, a que se trata de un sector de la juventud «supuestamente concienciado con el debate público». Entre las conclusiones, que tal vez constituyan uno de los planteamientos más sugerentes del libro, se destaca una secuencia de condiciones propicias a la movilización que rechaza el determinismo tecnológico y que nos previene contra la tentación «tecnofílica» de sobredimensionar la eficacia y el alcance de las nuevas tecnologías de la comunicación, puesto que la trivialización de la tecnopolítica podría desembocar en una pura autorreferencialidad (vid. asimismo p. 178). A pesar de evitar dicho determinismo, a la hora de abordar el detonante principal de las movilizaciones, esto es la frustración generada por la manifestación oficial del 12-M por cuanto supuso de apropiación política por parte del Gobierno (p. 74), dicho motivo no coincide con las tesis de los capítulos precedentes ni tampoco con la de muchos de los capítulos posteriores, ni se conjuga con las movilizaciones en otros lugares como en Barcelona donde sí se expresaron los sentimientos de descontento en la manifestación oficial. Cabe pues preguntarse, si el condicionante esencial en Madrid y Barcelona se contrapone (frustración de sentimientos vs. expresión de los mismos), ¿cómo se deduce el mismo resultado, la movilización del 13-M?

En el capítulo cuarto, dedicado al análisis del núcleo activista, la omisión de los criterios metodológicos de la técnica del grupo de discusión llega al paroxismo por cuanto se convoca jun único grupo! de cinco personas, dos de cuyos miembros son ¡los propios investigadores! Aquí ya no se puede argüir una proyección consciente y por tanto manipuladora de los investigadores sobre el objeto, sino de una proyección absolutamente cons- ciente, hasta el punto de que es el mismo debate, sin análisis de discurso y en su secuencia prácticamente lineal, el que queda plasmado a lo largo del capítulo a través de citas que abarcan páginas enteras. Tal vez se corresponde a un criterio metodológico militante que se filtra en muchos de los capítulos tal como luego se explicita: «estuvimos, estamos inmersos en los acontecimientos que investigamos» (p. 289). De nuevo, podemos incluso apreciar positivamente lo que de sustantivo tienen los planteamientos desgranados: el proceso de aprendizaje colectivo de las movilizaciones, la valoración crítica del comportamiento de los partidos institucionales, la incidencia política (no necesariamente medida en términos electorales) de la movilización social.

Todo eso está muy bien, pero hay tal vez un exceso de retórica comprometida al uso, plena de descripciones heroicas del «No a la guerra» con una fórmula fuertemente madrileñista por lo que tiene de etnocentrismo localista presente en la autoexplicación cómplice de los partícipes que a veces semeja al de militantes de un paraíso perdido que confunden la rebelión con la pretensión. Hay también en el relato del grupo una anticipación de las valoraciones al uso dentro de la militancia de aquello que se estudia, pero siempre se plantea el análisis de tales procesos desde su condición de militantes. Cabría recordar que el pensamiento crítico no es crítico porque condene a priori los efectos sobre las personas de los fenómenos y procesos que decide estudiar. Lo es porque piensa las raíces de la consistencia de lo real, muestra la relación entre lo vivido y los procesos de carácter general que son radicalmente sociales e históricos. Así, al localizar la condición de posibilidad de los fenómenos, señala los espacios para una acción eficaz y transformadora. De todas formas, el mayor problema de dicho análisis, aplicable 
en diverso modo a los anteriores capítulos, sigue siendo ¿por qué la molestia en realizar todo este trabajo de campo apresurado y torpe si no es para lograr una legitimación objetivante de las tesis que sostienen sus autores?

Los capítulos quinto y sexto se plantean un análisis cuantitativo de los medios de comunicación comparando las audiencias en informativos televisivos, las visitas a medios digitales de los grandes medios de comunicación (prensa escrita, digital y radio) con las visitas a medios de «contra-información» y «de carácter alternativo» (aspectos que nunca quedan bien delimitados $)^{4}$, y dado que estas últimas aumentan proporcionalmente más que las primeras se concluye que hemos asistido a un «climax inesperado», a la «parálisis de la esfera pública central» y por tanto a la «deliberación celérica desde la periferia» que escoge a su propio público caracterizado por «a) un grado de implicación en los asuntos políticos por

${ }^{4}$ En un momento dado se nos indica, tal vez a modo de definición, que los medios alternativos movilizaron la opinión pública discursiva: «un proceso, donde el público es un colectivo de voluntades individuales que deliberan entre sí, condicionándose mutuamente», lo cual identificaría a alguno de ellos por su estructura más abierta y enfocada a la participación y la movilización (Indymedia Barcelona y tal vez Indymedia Madrid) pero no a otros como Nodo50, Rebelión.org o el puñado de weblogs escrutados que actúan más bien como un periódico. De todas formas, ¿no hay más medios «alternativos» que los citados?, ini siquiera radios, prensa u otros? ¿o de nuevo nos encontramos con una metodología perezosa que tan sólo escoge entre lo conocido? Por cierto, no será la única definición de dicho concepto, pues en un momento dado encontraremos, en un cambio de registro notable, que la opinión pública discursiva se produce cuando se acepta que temas y argumentos ignorados por los políticos con opción de gobernar, son también ignorados por los periodistas de estos bloques mediáticos. encima de la media; b) su facilidad para ejercer de "líderes de opinión" en su entorno; y c) un sano escepticismo, en sentido amplio, respecto del periodismo con-

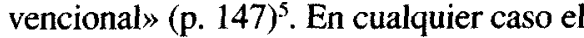
problema no es tanto la falta de explicación de tales presupuestos, sino las cifras totales y no los aumentos porcentuales, lo cual echa por tierra la supuesta parálisis de la esfera pública central. ¿Cómo es posible comparar durante los días $11 \mathrm{y}$ 14 de marzo las audiencias millonarias de los informativos televisivos superiores a los tres millones de televidentes, o la influencia de medios digitales como $E l$ Mundo, ABC, El Periódico, El Correo o la Cadena Ser con millones de páginas visitadas; con el incremento de unos pocos centenares de visitas de las weblogs a un par de miles, o de unos pocos miles de visitas en medios de contra-información a su doble? Que los medios convencionales no movilizaron la supuesta «opinión discursiva crítica» (cuya nueva definición parece ser algo así como «la nuestra», propia de un público «activista», «interesado en trascender el plano comunicativo", vid. nota 4) es obvio y para ello no hace falta remitirnos al 13-M. Pero resulta inverosímil, con las cifras aportadas, que eso haya supuesto una alteración de «la esfera pública para generar un nuevo proceso de formación de opiniones» (p. 119); a no ser que se redefina el concepto de esfera pública, aunque no parece el caso puesto que después, para caracterizar las exclusiones sobre el concepto sinónimo en términos comunicativos, el espacio público parece reducirse a los principales periódicos y medios convencionales. De todos modos, ¿cuál es la situación posterior de esa «esfera pública periférica» de carácter alternativo, con-

${ }^{5}$ No sabemos cómo ni porqué los atributos del público siguen esta curiosa taxonomía, a no ser que los autores conozcan a los componentes de dicho público personalmente. 
trainformativo y no institucional?, ¿han logrado consolidarse aquellos espectaculares aumentos para superar el espacio del «público activista» incondicional y lograr la «alteración de la esfera pública»?, ¿han proliferado las esferas públicas periféricas complementarias e incluso contrapuestas a la comunicación convencional? Dado que la respuesta a estas preguntas es negativa, el problema no es directamente achacable a dicha esfera pública periférica, sino a lo teatral de las afirmaciones aquí vertidas.

El capítulo séptimo parece continuar el análisis de los medios alternativos pero en realidad, así lo indica desde el principio, se trata de una «reivindicación» que reclama para las redes sociales «el protagonismo de la concentración que mantuvo rodeadas - durante horas- algunas sedes y muchas conciencias en la jornada de reflexión de las elecciones generales» de marzo (p. 183). Lo curioso es que no se vuelve a hablar de las redes sociales hasta el final, y que a pesar de una considerable producción de datos cuantitativos ni se analiza su relación con dicha movilización, ni menos aún la alteración de las conciencias en cuanto al voto. En realidad la parte central del artículo se basa en un análisis de las noticias aparecidas entre los días 11 y 13 de marzo de 2004 en cuatro medios «alternativos»: dos contra-informativos (publicaciones moderadas a cargo de un equipo editorial, de uno de los cuales forman parte los autores) y dos herramientas de publicación abierta, que aunque se consideran los más consultados no lo son -no se nos proporciona ninguna cifra al respecto-, pero basta con ver la tabla 5.12 (p. 156).

Más allá del sesgo de elegir estos cuatro medios, el problema del análisis comienza pronto en la selección de categorías utilizadas para identificar los artículos publicados: no son exhaustivas ni excluyentes pues albergan espacios de significación comunes, algunas son explícitamente ambiguas ${ }^{6}$, y en cualquier caso de dudosa aplicación a las noticias, puesto que muchas de estas últimas por su simple extensión e intensidad se podían calificar con varias categorías. Se trata además de un criterio cuantitativo tosco, que no califica a una noticia a través de un análisis de discurso o contenido, sino a través de una etiqueta que identifica todo su contenido independientemente de la intensidad o razones que en él se aduzcan. Problema también grave es la proliferación de categorías (hasta 14) para establecer una taxonomía sobre 363 noticias en cuatro medios y a lo largo de tres días ( $14 \times 4 \times 3=168$ casillas posibles) con lo que las cifras absolutas en cada casilla son mínimas y su variación porcentual, máxima. En realidad todo esto ha servido para comenzar una valoración muy positiva de lo propio (Nodo50) y una descualificación de Indymedia Madrid la cual, desde el principio y dado su bajo nivel de actividad en forma de mentira prudente, queda calificado como medio no «atractivo para las grandes organizaciones", o que su crítica al Gobierno y al Partido Popular es más dé-

\footnotetext{
${ }^{6}$ ¿Qué decir de la categoría «Emotivo-instrumental» que adjudica la autoría de los atentados del 11-M a ETA «e instrumentaliza las emociones y la empatía con las víctimas, para responsabilizar a ciertos sectores de la izquierda por su supuesta condescendencia con los nacionalismos...», o la de AETA «que imputan los atentados a ETA», o la de Mentiras Prudentes «que responsabiliza a ETA, sin contar con datos que lo avalen, pero que viene forzada por la presión de un clima político y mediático hostil»? También es enteramente cuestionable la categoría «Pérdida de referencias políticas», como reacción conmocionada por los atentados y la adjudicación a ETA y que supone la ruptura «político-afectiva con la izquierda abertzale». Veremos la importancia de semejantes definiciones después para desacreditar uno de los medios analizados.
} 
bil porque aparecen menos noticias que caigan bajo esta categoría.

Tras un primer acercamiento y descontentos los autores por la poca claridad de los resultados, se establece un reagrupamiento de las categorías sobre tres nuevas etiquetas: «supera el bloqueo mediático», «reproduce el bloqueo mediático» $y$ «elemento neutro» que cabe considerar discutible. En principio porque se da por establecido un «bloqueo mediático» que no parece seguirse ni siquiera en todos los medios convencionales, al menos durante los tres días analizados. Además estas nuevas categorías actúan como una simplificación íntegra de lo ya previamente simplificado en la calificación de las noticias. Por último porque se utilizan las tácticas propias del gerrymandering político ${ }^{7}$ para agrupar, de nuevo en reductivos términos cuantitativos, y en torno a la despreciada y despreciable «reproducción del bloqueo mediático» a las categorías que casualmente correspondían a uno de los medios alternativos. Ello lleva a la renovada descualificación de Indymedia Madrid como una mala «herramienta (...) dentro del ámbito político y comunicativo en el que convive» que aporta poco a la reflexión crítica que desembocó en el 13-M.

Hasta aquí la manipulación técnica de los datos puede pasar más o menos desapercibida para una mirada profana, pero insatisfechos los autores con esto, lo que viene a continuación es un ejemplo evidente de deshonestidad intelectual al establecer un sesgado paralelismo entre el artículo de Fernando Savater publicado

\footnotetext{
${ }^{7}$ Se trata de la agrupación o dispersión tendenciosa de áreas de voto a determinados distritos electorales con ánimo de manipulación. En este caso cabe preguntarse porqué el «desconsuelo y dolor» ante los atentados se considera «neutral», o las «llamadas a la calma» no reproducen el «bloqueo mediático», pero la «autoría atribuida a ETA» durante el 11-M sí lo hacen.
}

en El País el 12 de marzo y el supuesto carácter «emotivo-instrumental» de Indymedia Madrid, debido a que como indica la nota 17 o se repite después en la página 222, el propio hijo de Fernando Savater es miembro activo del colectivo editorial de este medio, lo cual explica que se le presente como «un colectivo permeable (desde su propio núcleo dirigente) a la presión mediática del Gobierno» del PP. El tono rencoroso del capítulo y la mala fe que destila esta acusación se podría volver contra los propios autores, pero lo mejor será no caer en una falacia ad hominem semejante a la que ellos lanzan.

El resto del artículo vuelve a insistir en una curiosa y patética propuesta que invierte, pero al mismo tiempo participa de, la imputación cainita del Ministro del Interior del momento: aquí sería que quien el día 11-M apuesta por la autoría de ETA no sirve a los intereses de la causa alternativa. $Y$ por otra parte se reproduce la casuística madrileña de la convocatoria de la movilización del 13-M aunque sólo parece tenerse una constancia narcisista de los acontecimientos vividos. Por último, las conclusiones no se siguen del análisis realizado, por lo que se nos antojan no como conclusiones, sino como preguntas sin resolver: ¿por qué son estos medios los que rompen el bloqueo informativo?, ¿hubo tal bloqueo todos los días?, ¿por qué conforman «un ejercicio responsable de militancia cívica»?, ¿cómo se han identificado sus públicos específicos de redes sociales activas movilizadas en torno a un ciclo de protestas y que culmina con «el ciclo de la antiglobalización»?, ¿cómo se puede hablar de la apertura de la estructura de oportunidad política si desemboca en unas elecciones generales convencionales con alternancia bipartidista?, ¿se han analizado el resto de medios de comunicación para hablar del «cierre de la estructura de oportunidad mediática en medios convencionales?, ¿o se trata, todo ello, de mera retórica? 
Los dos últimos capítulos, unidos conceptualmente al capítulo primero, y firmados además por el editor del libro Víctor F. Sampedro, siguen el ciclo de movilizaciones y se adentran en la obsesión por la desobediencia civil que identifica aquello recurrente o bien intencionado en forma de brote más o menos espontáneo y que participa plenamente de la ideología ciudadanista. Como indica Alain C. «Por ciudadanismo entendemos en principio una ideología cuyos rasgos principales son 1) la creencia de que la democracia es capaz de oponerse al capitalismo 2) el proyecto de reforzar el Estado (o los Estados) para poner en marcha esta política 3) los ciudadanos como base activa de esta política». Todos estos rasgos aparecen, si seguimos a Sampdro, en la «multitud on line» de aquella semana aunque con rasgos en ocasiones esotéri$\cos$ y siempre antropomórficos, como cuando se afirma se «la multitud se autoconvocó» (p. 259), o que la desobediencia civil (característica esencial de la coyuntura de aquella multitud) «sopesa no vulnerando la legalidad más que lo estrictamente necesario» (p. 269). Cabe preguntarse de qué actores se habla para atribuirles un predicado activo, pero sin parar mientes en eso y para demostrar que son identificables y hasta cierto punto equiparables, pues a fin de cuentas se trata de la representación social de un drama, se les pueden incluso imputar intereses. Así en la tabla 8.5 (p. 264), aparecen los cinco actores principales (gobierno, medios convencionales, oposición, terroristas y convocantes de las manifestaciones del 13-M) y «sopesan» las utilidades de sus intereses, en la forma de un superficial juego de rol: así el gobierno quería triunfar en las elecciones, planteando un clima de unidad y patriotismo constitucional, expresándose a través de una imagen de responsabilidad y transparencia; frente a los convocantes que reclamaban la verdad antes de votar, escenificaban el malestar cívico y el dolor, y se expresaban a través de la desobediencia civil no violenta (e incluso se llega al ridículo de contabilizar sus lemas y pancartas en las manifestaciones, $\mathrm{pp}$. 273-274). De todos modos el problema menor tiene que ver con la superficialidad de tal análisis, que asigna papeles autónomos, homogeneizantes y cuasi conscientes a los actores ( ilo son verdaderamente?, ¿siguen existiendo una semana después?, ¿,son los convocantes/ desobedientes la multitud?) en un escenario límpido, no estructurado y que recuerda en parte la «comunidad ideal de habla» de J. Habermas. Pero tal vez el inconveniente mayor estriba en que, dada tal identificación de intereses, lo que subyace a la relación de esta multitud coyuntural con el Estado y el resto de actores institucionales es a un aspecto a la vez de oposición y de apoyo crítico. Puede oponerse al Estado, pero no puede prescindir de la legitimidad que le ofrece, una movilización que deben convertirse rápidamente en interlocutores y para ello, algunas veces deben emprender acciones «radicales», es decir, ilegales o espectaculares. Así se responde a la pregunta «¿qué querían los desobedientes? Nuestra respuesta es sencilla, recuperar el protagonismo perdido en una campaña (...). Recuperar la voz, después que los rituales de poder se enmascarasen de luto». Se trata a la vez de situarse en posición de víctima, de coger al Estado en falta (es decir, oponer el Estado ideal al Estado real) y de llegar lo más rápidamente posible a la mesa de negociaciones, pero nunca sustituir a los poderes públicos. Como indica Alain C. en su panfleto "El impase ciudadanista», bajo estas premisas la finalidad expresa de este "ciudadanismo" es humanizar el capitalismo, volverlo más justo, proporcionarle de alguna forma un suplemento de alma.

La lucha de clases es sustituida aquí por «una demanda de mayor autonomía 
en el desarrollo de unos proyectos o estilos de vida que primero son privados» ( $\mathrm{p}$. 293) y luego públicos. El autor, en un ejercicio de metonimia intelectual, pasa entonces de los desobedientes a las multitudes, las cuales desempeñan aquí el papel otorgado anteriormente a los sindicatos en el mundo laboral, para todo lo que se denominaba «problemas sociales». La amplitud de la mistificación muestra también la amplitud del campo de la contestación posible, que se ha extendido a todos los aspectos de la sociedad. Ya no basta con introducir demandas en la agenda electoral de los partidos, sino que «El mensaje ambiguo de las multitudes permite que otros lo moldeen según intereses ajenos (...) No hay, por tanto, una acción colectiva dirigida a demandar la autogestión o a exigir y controlar ciertas políticas. Más bien se intenta expresar la autonomía de cada individuo, de cada grupo de afinidad» (p. 299). Una llamada a la subjetividad que cabe pensar no es una cuestión de impotencia, sino de reformismo, se le califique o no de cínico. Una desobediencia que no plantea una lucha por una alternativa radical, sino que tan sólo «responde al fallo de los canales de representación y debate democráticos. La multitud en sí misma denuncia a quienes se arrogan su voz»; por lo que el papel político y social de esta multitud es simplemente de queja y vigilancia: les transmite a sus representantes que dejen de considerarle mera clientela política que meramente elige a sus representantes, y trata además de actuar constantemente para hacer presión sobre ellos, con el fin de que apliquen aquello para lo que fueron elegidos. Hay también en ello, y sobre todo relacionándolo con la autoinculpación (vid. nota 2) y el cambio de registro verbal de la tercera persona del plural a la primera, una peligrosa confusión de la «multitud» del todos con el «nosotros» de los activistas al constatar que esas multitudes han sido realmente minoritarias y que han precisado de la conformación de un tejido autoorganizado y consciente previo.

En definitiva y para concluir, aunque caben destacar del libro su oportunidad, el rechazo del determinismo tecnológico o a revivir épicas metáforas revolucionarias, así como su loable esfuerzo de trabajo empírico, debemos considerar que se trata de una oportunidad perdida para evaluar de forma exhaustiva lo acontecido en aquellos días, de modo que comprobar cómo funciona la «multitud» sigue siendo un problema pendiente. Quizá sea un problema del mismo concepto o de su correlación empírica e histórica. Nos quedamos con la duda.

Mario Domínguez Sánchez Profesor de Sociología de la UCM 